\title{
PRIMARY SARCOMA OF THE PERICARDIUM
}

BY

\author{
ROBERT P. TOWERS AND RISTEÁRD MULCAHY
}

\author{
From the Departments of Pathology and Cardiology, St. Vincent's Hospital, Dublin
}

We report this case of primary sarcoma of the pericardium because of its rarity and because a confident diagnosis of chronic constrictive pericarditis had been made in life, the correct diagnosis being made only at necropsy. Reference to standard works on cardiology reveals that primary tumour of the pericardium is not discussed and is not included in the differential diagnosis of constrictive pericarditis (White, 1951; Wood, 1956).

\section{Case Report}

The patient, a man aged 45, was admitted to St. Vincent's Hospital on March 7, 1960 from a country hospital with a provisional diagnosis of pleural effusion. He was a carpenter and occasional farmhand, and had been in perfect health until four months previously. His personal and family history was clear, with nothing to suggest tuberculosis.

On admission he complained of an unproductive cough associated with central pericardial or pleuritic type of pain. He had one or two bouts of dyspnœa at rest a few months previously and was now obviously orthopnœic. He had had ankle odema before admission. He complained of lassitude, anorexia, gross loss of weight, and night sweats, but not of hæmoptysis.

On examination he had the classical signs of constrictive pericarditis, with signs of an extensive rightsided pleural effusion. The apex beat was impalpable, the pulse was fairly rapid and small, and there was an easily identified pulsus paradoxicus with disappearance of the pulse on deep inspiration. The blood pressure was $105 / 80 \mathrm{~mm}$. Hg. The venous pressure was high, and the small damped pulsations in the

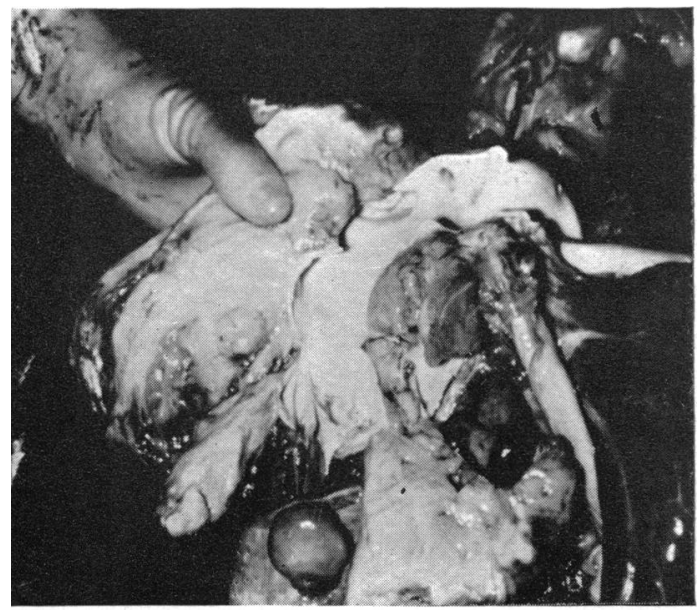

FIG. 1.-A photograph of the gross specimen at necropsy, showing the tumour encasing the ascending aorta. A sessile nodule of growth on the ventricle is also seen.

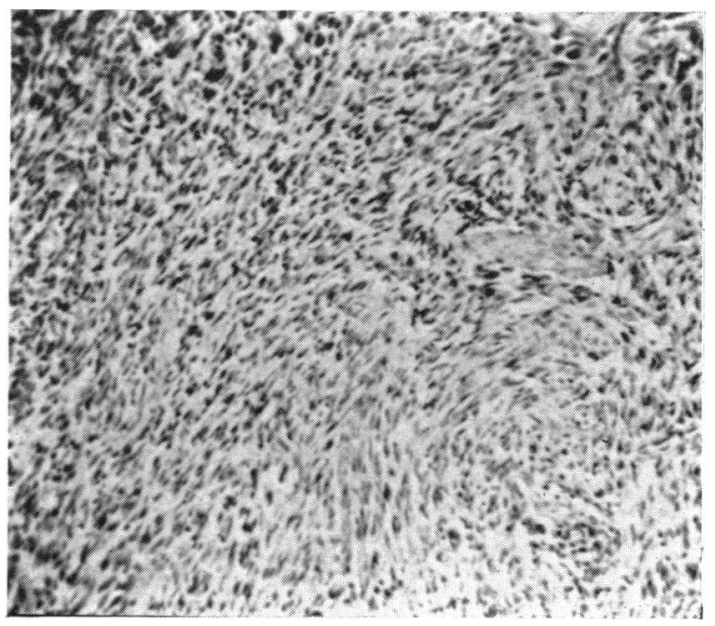

Fig. 2.-A representative section showing the microscopical structure. (Hæmatoxylin and eosin. $\times 70$.) 
jugular veins were difficult to identify. The liver was doubtfully enlarged, and there was some ascites and minimal ankle œdema. There was marked peripheral cyanosis.

Special Investigations. The electrocardiogram showed sinus tachycardia, low voltage, and isoelectric T waves. The hæmoglobin was $11 \cdot 1 \mathrm{~g}$. per $100 \mathrm{ml}$., leucocytes 5250 with 81 per cent polymorphs. The erythrocyte sedimentation rate averaged $29 \mathrm{~mm}$. (Westergren). Serum proteins, electrolytes, and blood urea were within normal limits. Sputum examination was negative for tubercle bacilli. Repeated examination of pleural, pericardial, and peritoneal fluids failed to reveal tubercle bacilli or tumour cells; the pericardial fluid was not blood-stained.

A confident diagnosis of constrictive pericarditis, probably of tuberculous origin, was made, and treatment was started with antituberculous drugs. Despite the addition of diuretics and repeated pleural aspiration, the patient's condition deteriorated, and he died on May 7, 1960, two months after admission.

Necropsy. The examination was made about six hours after death. The body was that of a tall, wellbuilt man, with œdema of the lower limbs and scrotum, and a rather distended abdomen.

There was a large amount of yellowish fluid in both pleural cavities, rather more on the right side. Both lungs were partly collapsed, and there were several infarcts in the right lung. The trachea and main bronchi contained a small excess of mucoid secretion and examination revealed no evidence of tumour. The pericardial sac was enormously distended and felt hard. On opening it, only nodular masses of greyish-yellow tumour could be seen, the heart being unrecognizably buried. Upon dissection, the main site of origin of the growth appeared to be in the region of the base of the heart, the aorta and pulmonary artery being encased by growth for several centimetres. A large tongue of tumour extended through the transverse sinus and a large partly necrotic portion was dependent from the main mass. Several smaller nodules of tumour were seeded over the surface of the ventricles. The parietal pericardium was thickened and showed fibrinous deposits. A small nodule of tumour in the right posterior wall of the pericardium was visible on the outer surface. The valves and chambers of the heart were anatomically normal, and the coronary arteries were patent. The aorta and great vessels showed little or no atheroma, and the great veins were normal. . There was no connexion between the pericardium and other mediastinal structures to suggest spread from another site of origin.

The liver showed marked chronic venous congestion, and there was a small quantity of yellowish fluid in the peritoneal cavity. Apart from congestion, the other abdominal organs appeared within normal limits, as were the cranial contents except for excessive moistness of the left middle ear.

Sections of all the organs revealed congestive changes only. Multiple blocks (some twelve in number) of the pericardial tumour were made, and sections were stained by hæmatoxylin and eosin, by iron-hæmatoxylinvan Gieson, by Masson's trichrome method, and by Mallory's phosphotungstic acid-hæmatoxylin. The multiple sections showed a fairly uniform pattern of interlacing bundles of elongated spindle cells, with nuclear pleomorphism and a number of mitoses in some areas. After examining sections stained by hæmatoxylin and eosin, the diagnosis was considered to lie between a leiomyosarcoma and a fibrosarcoma. Neither the cleft-like formations nor the epithelial elements described under the heading of "mesothelioma" were seen. Mallory's PTAH stain revealed no myofibril formation, and connective tissue stains demonstrated the presence of collagen fibres. The tumour was, therefore, considered to be a fibrosarcoma of low to moderate grade of histological malignancy.

Death was, of course, attributed to the constrictive effects of the tumour.

\section{Comment}

A case of apparent constrictive pericarditis in a man aged 45 is reported, causing death within six months of the onset of symptoms. At necropsy, a fibrosarcoma of the pericardium was found.

Mahaim (1945) in reviewing malignant disease of the pericardium collected 20 cases of sarcoma, while Dawe, Wood, and Mitchell (1953) added a further four. Primary sarcoma of the pericardium is, therefore, extremely rare. It should, however, be considered in the differential diagnosis of constrictive pericarditis when the degree of heart enlargement is unusual.

We are grateful to Dr. Harold Quinlan for permission to publish this case.

\section{References}

Dawe, C. J., Wood, D. A., and Mitchell, S. (1953). Cancer (Philad.), 6, 794.

Mahaim, I. (1945). Les Tumeurs et les Polypes du Coeur: Etude anatomo-elinique. Masson, Paris, and Roth, Lausanne. White, P. D. (1951). Heart Disease, 4th ed. Macmillan, New York.

Wood, P. (1956). Diseases of the Heart and Circulation, 2nd ed. Eyre and Spottiswoode, London. 